\author{
Magdalena Gorzelany-DziadKowiec \\ Uniwersytet Ekonomiczny w Krakowie, Polska - Cracow University of Economics, Poland \\ KRZYSZTOF FIRLEJ \\ Uniwersytet Ekonomiczny w Krakowie, Polska - Cracow University of Economics, Poland
}

\title{
Wykorzystanie mediów społecznościowych w komunikacji marketingowej przez małe przedsiębiorstwa
}

\section{The use of social media in marketing communication of small enterprises}

\begin{abstract}
Streszczenie: Celem niniejszego opracowania jest analiza wykorzystania mediów społecznościowych w komunikacji marketingowej przez małe przedsiębiorstwa. Dla zrealizowania celu dokonano systematycznego przeglądu literatury w bazach Scopus i Google Scholar opublikowanych w latach 2018-2021 w języku angielskim. Uzupełniająco przeprowadzono tradycyjny przegląd literatury zarówno polskiej, jak i zagranicznej, raportów oraz danych statystycznych. Dodatkowo przeprowadzono badania własne, które miały charakter badań ankietowych - sondażu diagnostycznego. Jako narzędzie badawcze wykorzystano autorski kwestionariusz zawierający metryczkę oraz pytania zamknięte. Odpowiedzi od respondentów zebrano metodą CAWI. Wnioski, które wyciągnięto, są następujące: najczęściej badane przedsiebiorstwa komunikują się z rynkiem poprzez portal społecznościowy Facebook, następnymi wskazynymi przez respondentów środkami komunikacji były Messenger i Instagram, w małym stopniu w komunikcji z rynkiem małe przedsiębiorstwa wykorzystywały aplikację WhatsApp oraz serwis YouTube, natomiast nie korzystały ze Snapchatu i WeChatu. Wartością dodaną artykułu są implikacje dla małych przedsiębiorstw związane z podejmowaniem lepszych decyzji dotyczących wykorzystywania mediów społecznościowych (social marketingu) w komunikacji z rynkiem.
\end{abstract}

Abstract: The aim of this study was to analyse the use of social media in marketing communication of small enterprises. To achieve the goal, a systematic literature review was carried out in the Scopus and Google Scholar databases published in 2018-2021 in English. Complementarily, a traditional review of both Polish and foreign literature, reports and statistical data was carried out. Additionally, own research was carried out in the form of questionnaires - a diagnostic survey, an original questionnaire containing a record and closed questions was used as a research tool. Responses were collected using the CAWI method. The conclusions that were made are as follows: the surveyed enterprises most frequently communicate with the market via Facebook, the next most common market communicators indicated by the respondents are Messenger and Instagram, WhatsApp and YouTube are used by small enterprises in small extent, Snapchat and WeChat is not used in communication with the market in small businesses at all. The added value of the article is the implications for small businesses, that they can make better decisions regarding the use of social media (social media marketing) in communication with the market. 
Słowa kluczowe: komunikacja marketingowa; komunikacja z rynkiem; małe przedsiębiorstwa; media społecznościowe

Keywords: communication with the market; marketing communication; small enterprises; social media

Otrzymano: 28 luty 2021

Received: 28 February 2021

Zaakceptowano: 1 września 2021

Accepted: 1 September 2021

\section{Sugerowana cytacja/Suggested citation:}

Gorzelany-Dziadkowiec, M., Firlej, K. (2021). Wykorzystanie mediów społecznościowych w komunikacji marketingowej przez małe przedsiębiorstwa. Przedsiębiorczość - Edukacja [Entrepreneurship - Education], 17(2), 36-50. https://doi.org/10.24917/20833296.172.3

\section{Wstęp}

Rozwój technologiczny spowodował w pierwszej dekadzie nowego millenium zasadnicze zmiany zachowań użytkowników w zakresie tworzenia i pozyskiwania informacji. Współczesna gospodarka, nosząca miano cyfrowej, zapewnia sprawne funkcjonowanie i stosowanie nowoczesnych technologii, które wymagają właściwego wykorzystania technologii informacyjnych, w tym mediów społecznościowych, przez osoby zarządzające. Celem niniejszego opracowania jest analiza wykorzystania mediów społecznościowych w komunikacji marketingowej przez małe przedsiębiorstwa. W badaniach zadano następujące pytania:

1. W jakim stopniu oraz które media społecznościowe są wykorzystywane przez małe przedsiębiorstwa do komunikacji marketingowej?

2. Jakie są zalety i bariery wykorzystywania mediów społecznościowych do komunikacji z rynkiem przez małe przedsiębiorstwa?

3. Jakie czynniki wpływają na podjęcie decyzji o wykorzystaniu Facebooka do celów marketingowych przez małe przedsiębiorstwa?

Dla zrealizowania postawionego celu i uzyskania odpowiedzi na postawione pytania przeprowadzono systematyczny przegląd literatury w bazach Scopus i Google Scholar opublikowanych w latach 2018-2021 w języku angielskim. Oceniono zarówno artykuły ilościowe, jak i jakościowe. Artykuły zostały przefiltrowane na podstawie ich znaczenia dla celu badania (wyszukiwano słów kluczowych: media społecznościowe, komunikacja marketingowa, komunikacja z rynkiem, social media, social media marketing, marketing wartości), w wyniku czego wybrano 84 pozycje. Do przeglądu systematycznego wybrano 28 pozycji. Uzupełniająco przeprowadzono tradycyjny przegląd literatury zarówno polskiej, jak i zagranicznej, raportów oraz danych statystycznych (25 pozycji). Dodatkowo zostały przeprowadzone badania własne, które miały charakter badań ankietowych - sondażu diagnostycznego. Jako narzędzie badawcze wykorzystano autorski kwestionariusz zawierający metryczkę oraz pytania zamknięte. Odpowiedzi od respondentów zebrano metodą CAWI. Celem badań ankietowych była analiza i identyfikacja mediów społecznościowych, które są wykorzystywane przez małe przedsiębiorstwa do komunikacji marketingowej $\mathrm{Na}$ tym etapie kwestionariusz stanowił narzędzie poznania faktów i opinii społecznej na temat problemu badawczego. Rezultatem tego etapu badań było uzyskanie wiedzy o tym, które media są wykorzystywane w największym stopniu do komunikacji 
marketingowej przez małe przedsiębiorstwa, jaki jest stopień ich wykorzystania oraz jakie są uwarunkowania ich wykorzystania w komunikacji z rynkiem w opinii przedstawicieli małych przedsiębiorstw. Wartością dodaną artykułu są implikacje dla małych przedsiębiorstw dotyczące podejmowania lepszych decyzji dotyczących wykorzystywania mediów społecznościowych w komunikacji z rynkiem.

\section{Komunikacja marketingowa - przegląd literatury}

Zmieniające się otoczenie oraz powstanie gospodarki opartej na wiedzy, nasilające się procesy globalizacyjne oraz dynamiczny rozwój technologii powodują, że przed organizacjami pojawia się coraz więcej wyzwań. Aby organizacje mogły przetrwać i rozwijać się, zarządzające nimi osoby poszukują nowych możliwości działania. T. Łuczka (2009) podkreśla, że rozwój małych przedsiębiorstw może być badany z punktu widzenia ich zdolności dostosowywania się do wyzwań i zmian warunków funkcjonowania, barier i ograniczeń rozwoju. Natomiast J. Pawlak (2016) zwraca uwagę, że postęp technologiczny wymaga zwłaszcza od mikro i małych przedsiębiorców wypracowania strategii działania oraz zaadaptowania najnowszych technologii oraz narzędzi komunikacyjnych, tak by stworzyć atrakcyjne dla klientów otoczenie zachęcające do nawiązania kontaktu oraz - przede wszystkim - skorzystania z oferty przedsiębiorstwa.

Procesy zarządzania w małych przedsiębiorstwach wymagają wielu informacji o rynku, klientach, konkurencji i innych elementach otoczenia. Wyzwaniem dla przedsiębiorcy jest sprzedaż swojego produktu. Oprócz kształtowania wizerunku musi on myśleć o promowaniu konkretnych produktów tak, aby przekonać do siebie klientów. Działalność marketingowa w małym przedsiębiorstwie rządzi się innymi zasadami, niż ma to miejsce w średnich i dużych przedsiębiorstwach. Wynika to ze specyfiki funkcjonowania małych przedsiębiorstw, jak również z takich cech, jak: mniejszy budżet na działalność marketingową, inna pozycja rynkowa niż średnich i dużych przedsiębiorstw, konieczność szybkiego zaadoptowania się do zmieniających się warunków otoczenia, wpływ osobistych celów i motywów osoby prowadzącej przedsiębiorstwo. W związku z powyższym można stwierdzić, że dostosowanie się małego przedsiębiorstwa do zmieniających się uwarunkowań technologicznych oraz umiejętne wykorzystanie narzędzi komunikacyjnych determinuje jego rozwój. Na wpływ mediów społecznościowych na funkcjonowanie i rozwój małych przedsiębiorstw wskazują G. Szymański (2010) oraz D. Janczewska (2018), natomiast A. Bojanowska (2018) przedstawia działania MŚP w mediach społecznościowych. Technologia, zwłaszcza technologia cyfrowa, zmieniła sposób prowadzenia biznesu na całym świecie. Procesy globalizacji wpływają na zachowania zarówno producentów, jak i konsumentów. Konsumpcyjny charakter i konsekwencje globalizacji niosą za sobą dyfuzję nowych form sprzedaży i zachowań klientów (Kozioł, Rudawska, 2007). Jednym z głównych wydarzeń w tym względzie było rozpowszechnienie się mediów społecznościowych, które A.M. Kaplan i M. Haenlein (2010) definiują jako wykorzystanie funkcjonalności Web 2.0 oraz umożliwienie i dostarczanie treści generowanych przez użytkowników multimediów. Bogate dane na portalach społecznościowych i platformach handlu elektronicznego zapewniają nowatorski sposób zarządzania przedsiębiorstwem. Uwagę na zależność pomiędzy zdolnością do wprowadzania zmian a mediami społecznościowymi zwrócili w swoich badaniach Y.Y. Wang, T. Wang oraz R. Calantone (2021), co zapoczątkowało zmiany w postrzeganiu komunikacji marketingowej, która stała się zjawiskiem społecznym na współczesnym rynku. 
Komunikacja przedsiębiorstwa $\mathrm{z}$ rynkiem musi być rozumiana, planowana i realizowana w nadrzędnych założeniach strategii biznesowej przedsiębiorstwa (Ju, 2018). Rozwój Web 2.0 i mediów społecznościowych stworzył nową erę marketingu, która odnosi się do rozszerzonej dziedziny marketingu relacji (Mušanović, Dorčić, Baldigara, 2021), która bardzo mocno przesunęła się w kierunku środowiska interaktywnego (Li, Larimo, Leonidou, 2020). Wiele przedsiębiorstw inwestuje w marketing cyfrowy, w celu zwiększenia zaangażowania klientów w mediach społecznościowych, inwestycje te często zapewniają szybki zwrot, ponieważ pozytywne interakcje z klientami w mediach społecznościowych zapewniają efekt domina, gdy rozciągają się od pojedynczego użytkownika do szerszej społeczności sieci (Kumar, Mirchandani, 2012). M.S. Siddiqui oraz U.A. Siddiqui i inni (2021) zwracają uwagę na fakt, że komunikacja za pośrednictwem poczty pantoflowej zwykle odgrywa kluczową rolę w wywieraniu i kształtowaniu postaw konsumentów i zachowań. Internet zmienił sposób, w jaki się komunikujemy (James, Bradley, 2021). Zagadnienie dotyczące efektywnego wykorzystania mediów społecznościowych jako narzędzia odpowiedzialnej i zrównoważonej polityki komunikacji przedsiębiorstwa z rynkiem jest przedmiotem intensywnych badań od ponad dekady (Gyenge et al., 2021; Lijuan, Xiangbin, 2021; Luther et al., 2017; Marušić, Vranesevic, 2021; Nuseir, Qasim, 2021).

Z punktu widzenia wielu autorów skuteczna komunikacja marketingowa przedsiębiorstwa jest jednym z fundamentów sukcesu rynkowego (Fine, Grönroos, 2009; Hänninen, Karjaluoto, 2017). Proces komunikacji znalazł się w polu zainteresowania takich dyscyplin naukowych, jak: filozofia, historia, geografia, psychologia, socjologia, etnologia, ekonomia, nauki polityczne, biologia, cybernetyka oraz nauki o poznaniu i komunikacji społecznej. Wspólne dla wymienionych nauk jest rozumienie procesu komunikacji jako aktu przekazywania określonej treści - komunikatu, treści komunikatu czy treści komunikowanej i odbieranej (Mattelart, 2001).

Komunikacja marketingowa jest procesem wymiany informacji między podmiotami rynku i, w odróżnieniu do promocji, ma charakter interaktywny (Wodyński, 2007), kreuje świadomość, dostarcza wiedzę i motywuje do zakupu produktu. Warto wspomnieć o komunikacji perswazyjnej, która pozwala pokonać bariery określane jako chęci posiadania produktu (Kijewska, Mantura, 2017). W teorii komunikacji odnajdujemy jej modele, w których wskazuje się istotne elementy, strukturę oraz cele procesów komunikacji (Wiktor, 2013). W literaturze dotyczącej marketingu komunikację marketingową najczęściej odwzorowuje się przez określony układ elementów, takich jak: nadawca, przekaz, medium, odbiorca (m.in. model komunikacji interpersonalnej, model komunikacji masowej, model komunikacji w hipermedialnym środowisku komputerowym czy jedno-, dwu- lub wielostopniowe modele komunikacji marketingowej) (Kijewska, Mantura, 2017). Działaniom tym sprzyja digitalizacja, rozwój Internetu, za pomocą którego łączą się już blisko 2/3 globalnej populacji, czyli ok. 4 mld 390 mln osób. W 2018 roku ok. $367 \mathrm{mln}$ po raz pierwszy połączyło się z siecią, a dziennie przybywało prawie milion internautów. Według danych zawartych w raporcie Global Digital 2019, przygotowanym przez We Are Social i Hootsuite, w 2018 roku o ponad 280 mln wzrosła liczba użytkowników mediów społecznościowych. Korzysta z nich prawie 45\% populacji, czyli ok. 3,5 mld osób. Niewiele mniej, bo 42\%, robi to za pośrednictwem urządzeń mobilnych (Mirek, 2019).

Platformą komunikacji stały się media społecznościowe. W literaturze można odnaleźć stwierdzenie, że jest to wspólna mównica skupiająca dwóch członków, np. klientów i dystrybutorów internetowych, gdzie te osoby wymieniają dane (Touchette, Schanski, 
Lee, 2015). Media społecznościowe to jedno z najważniejszych miejsc do prowadzenia działań marketingowych przez przedsiębiorstwa (Chu, Deng, Cheng, 2020), gdyż zapewniają one szybki przepływ informacji - szybkość komunikacji (Marušić, Vranesevic, 2021). W mediach społecznościowych zawsze było coś cennego - czas. Czas na komunikację, czas na tworzenie kampanii marketingowych, czas na rozwój i ewolucję. Komunikacja stałą się zatem szybka, globalna, udostępniona wszystkim do obejrzenia i komentowania dzięki mediom społecznościowym (Pollák, Markovic, 2021), jest dynamiczna, połączona, egalitarna i stanowi interaktywny organizm (Mušanović, Dorčić, Baldigara, 2021). Media społecznościowe pozwoliły na połączenie przedsiębiorstw z klientami za pośrednictwem różnych platform, które pozwalają na budowanie wspólnych zainteresowań i wartości. Powiązanie to można określić jako silne lub słabe więzi społeczne (Li, Larimo, Leonidou, 2020). Media społecznościowe ze swoją interaktywną funkcją stały się ważnym miejscem, w którym klienci mogą angażować się w zarządzanie relacjami z klientami (Ashley, Tuten, 2014; Cheng et al., 2021), w tym w społeczną odpowiedzialność biznesu (CSR), który został doceniony jako ważny element brandingu (Moliner et al., 2020; Wang, Huang, 2018).

Na zakończenie rozważań tej części opracowania sformułowano wniosek, że w ostatnich latach nastąpiły zmiany w kierunku wykorzystywania mediów społecznościowych. Media te są stosowane do celów marketingowych, głównie do komunikacji z rynkiem, i zaczęły determinować rozwój przedsiębiorstw.

\section{Media społecznościowe w liczbach}

Według raportu Digital in 2020, w styczniu 2020 w Polsce było 30,63\% mln użytkowników Internetu, co pozwala stwierdzić, że w latach 2019-2020 liczba osób korzystających z Internetu w naszym kraju wzrosła o 686 tys. (+2,3\%). Aktywnymi użytkownikami mediów społecznościowych jest $19 \mathrm{mln}$ osób. To z kolei połowa całkowitej populacji naszego kraju. Już 97\% z nas robi to z poziomu urządzenia mobilnego, a od $2019 \mathrm{r}$. do sieci społecznościowych dołączyło 1,4 mln użytkowników (+7,8\%). Z Facebooka, WhatsAppa, Instagramu i Messengera korzysta każdego miesiąca 2,7 mln użytkowników. W ramach strategii marketingowej coraz większa liczba polityków wykorzystuje media społecznościowe do informowania swoich wyborców. Wśród polityków w dużym stopniu rozpowszechniony jest Twitter (Petrova, Sen, Yildirim, 2021).

Korzystanie z Internetu to współcześnie nieodłączny element naszego życia. Internet jako medium stał się dla nas miejscem pracy, nauki, rozrywki. Na popularności zyskały i zyskują nadal portale społecznościowe, stanowiące nowoczesną metodę zawierania i podtrzymywania znajomości, ale również będące miejscem prowadzenia kampanii reklamowych bądź elementem budowy strategii komunikacji z rynkiem.

\section{Wykorzystanie mediów społecznościowych w świetle przeprowadzonych badań}

Na silny związek zarządzania z działalnością praktyczną zwraca uwagę M. Lisiński (2016), który podkreśla, że konieczne jest stałe podnoszenie rygorów naukowych w obszarze nauk o zarządzaniu, zarówno w zakresie gromadzenia i rozwijania wiedzy, jak i stosowania metod badawczych oraz procesu empirycznej weryfikacji teorii. Z tych względów, aby odpowiedzieć na postawione w niniejszym artykule pytania badawcze, przeprowadzono 
badania własne, które miały charakter badań ankietowych - sondażu diagnostycznego. Jako narzędzie badawcze wykorzystano autorski kwestionariusz zawierający metryczkę oraz pytania zamknięte. Odpowiedzi od respondentów zebrano metodą CAWI. Przyjęty cel badawczy w oczywisty sposób przełożył się na kryteria doboru próby badawczej. Analiza wykorzystania mediów społecznościowych do komunikacji marketingowej $\mathrm{w}$ małych przedsiębiorstwach domagała się objęcia badaniem małych przedsiębiorstw. Z tych względów kwestionariusz został umieszczony na dysku Google oraz rozesłany do pracowników i właścicieli małych przedsiębiorstw. Link do ankiety rozesłano drogą elektroniczną do 300 osób - przedstawicieli małych przedsiębiorstw. Badania własne były realizowane od 3 marca 2020 do 15 kwietnia 2021 r. Otrzymano 100 poprawnie wypełnionych kwestionariuszy Kwestionariusz ankiety składał się z metryczki oraz części zasadniczej. W metryczce zawarto pytanie dotyczące funkcji pełnionej w przedsiębiorstwie. Respondent miał do wyboru: właściciel, stanowisko kierownicze, pracownik. To pozwoliło zweryfikować, kto wypełniał kwestionariusz ankiety - w $80 \%$ byli to pracownicy, w 15\% - właściciele, a w 5\% - osoby zajmujące stanowisko kierownicze. Struktura badanych przedsiębiorstw została zobrazowana na rycinie 1.

Pierwsze pytanie, które zostało zadane w kwestionariuszu, dotyczyło wyboru narzędzi komunikacji z rynkiem i kanałów promocji. Wyniki zestawiono na rycinie 2.

Na podstawie analizy wyników przedstawionych na rycinie 3 zauważyć można, że $94 \%$ badanych przedsiębiorstw określiło, że komunikuje się z rynkiem za pomocą portali społecznościowych.

Przeprowadzone badanie empiryczne dotyczyło opinii przedstawicieli małych przedsiębiorstw na temat wykorzystania mediów społecznościowych w komunikacji z rynkiem. W trakcie trwania badania uczestników proszono o wyrażenie opinii wobec 28 stwierdzeń. Respondenci do udzielenia odpowiedzi wykorzystywali pięciostopniową skalę Likerta. Do opisu wyników zastosowano przekodowanie odpowiedzi na liczby naturalne: $\mathrm{w}$ bardzo dużym stopniu $=1, \mathrm{w}$ dużym stopniu $=2$, częściowo $=3$, w małym stopniu $=4$, zupełnie nie $=5$. Następnie wykonano jednoczynnikową analizę wariancji z poprawką Welcha (ANOVA). Otrzymano wynik $\mathrm{F}=15,948$ i $\mathrm{p}=0,000$ upoważniający do stwierdzenia, że różnice średniej oceny wykorzystania rozpatrywanych komunikatorów są istotne statystycznie. Zastosowany test post-hoc Scheffego wyróżnił trzy grupy średnich, które przedstawiono w tabeli 1.

Tabela 1. Grupy oceny wykorzystania komunikatorów w badanych przedsiębiorstwach

\begin{tabular}{|l|c|c|c|c|}
\hline \multicolumn{1}{|c|}{ Komunikator } & $\begin{array}{c}\text { Średnia ocena } \\
\text { wykorzystania } \\
\text { komunikatora }\end{array}$ & Grupa 1 & Grupa 2 & Grupa 3 \\
\hline Facebook & 2,00 & - & & $* * * *$ \\
\hline Messenger & 3,21 & - & $* * * *$ & - \\
\hline Instagram & 3,24 & - & $* * * *$ & - \\
\hline WhatsApp & 4,11 & $* * * *$ & - & - \\
\hline YouTube & 4,12 & $* * * *$ & - & - \\
\hline WeChat & 4,54 & $* * * *$ & - & - \\
\hline Snapchat & 4,60 & $* * * *$ & - & - \\
\hline
\end{tabular}

Źródło: Opracowanie własne 
Rycina 1. Struktura branżowa badanych przedsiębiorstw

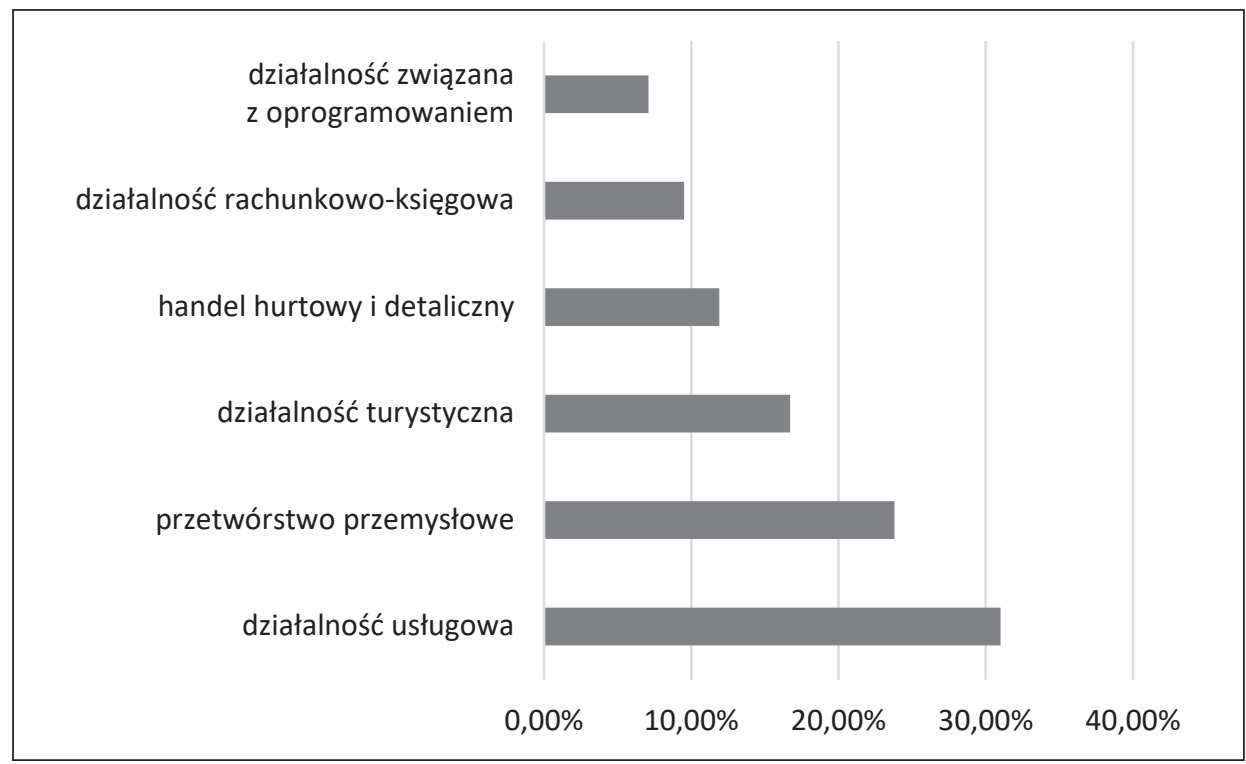

Źródło: Opracowanie własne na podstawie przeprowadzonych badań

Rycina 2. Narzędzia komunikacji marketingowej wykorzystywane przez badane małe przedsiębiorstwa

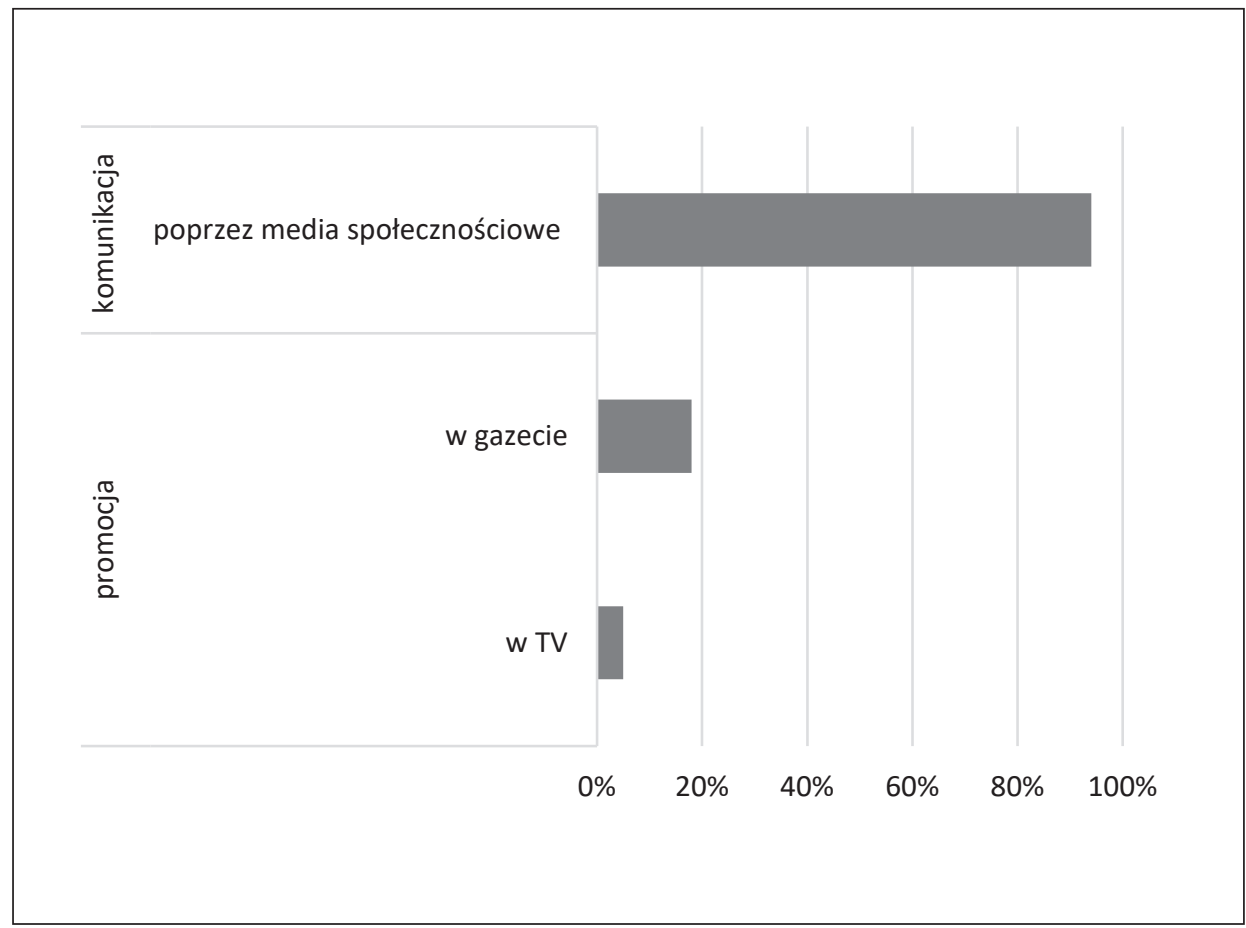

Źródło: Opracowanie własne na podstawie przeprowadzonych badań 
Analizując dane zawarte w tabeli 1, stwierdzić można, że w grupie 2 znajdują się Messenger i Instagram, których średnie oceny nie różnią się statystycznie istotnie. Facebook o średniej 2,00 stanowi osobną grupę, natomiast pozostałe komunikatory stanowią grupę 3. Średnie oceny wykorzystania poszczególnych komunikatorów wraz z 95-procentowymi przedziałami ufności przedstawiono na rycinie 3.

Na podstawie analizy zestawienia przedstawionego na rycinie 3 stwierdzić można, że najczęściej badane przedsiebiorstwa komunikują się z rynkiem za pośrednictwem Facebooka - średnia ocen wynosiosła 2. Następnymi wskazanymi przez respondentów komunikatorami były Messenger i Instagram (średnia ocen 3,21-3,24). W mniejszym stopniu w komunikcji z rynkiem małe przedsiębiorstwa wykorzystywały WhatsAppa oraz YouTube’a (średnia ocen 4,11-4,12), natomiast nie jest wykorzystywały w komunikacji z rynkiem Snapchatu i WeChatu. Stwierdzić zatem można, że najczęsciej w komunikacji $\mathrm{z}$ rynkiem małe przedsiebiorstwa wykorzystują Facebook.

W kolejnym kroku badań poszukiwano odpowiedzi na pytanie o to, jakie są uwarunkowania wykorzystywania mediów społecznosciowych w komunikacji z rynkiem przez małe przedsiębiorstwa. Wyniki badań zobrazowano na rycinie 4.

Analiza wskaznego obszaru pozwala ustalić, że w opnii badanych przedstwicieli małych przedsiębiorstw zaletami wykorzystania mediów społecznosciowych do komunikacji z rynkiem przez mikro- i małe przedsiębiorstwa jest duża liczba odbiorców (85\% badanych przedsiebiorstw) oraz łatwość umieszczania treści (83\% badanych przedsiębiorstw), możliwość umieszczania zdjęć (79\% badanych przedsiębiorstw), możliwość przekazania informacji w czasie, w którym się chce (71\% badanych przedsiębiorstw), niskie opłaty (65\% badanych przedsiębiorstw), możliwość komentowania przez klientów (57\% badanych przedsiębiorstw). Bariery w komunikacji z rynkiem przez media społecznościowe w opinii respondentów zobrazowano na rycinie 5.

Wśród barier pojawiających się podczas komunikacji z rynkiem za pośrednictwem mediów społecznościowych $46 \%$ badanych wskazało zagrożenie, jakim jest możliwość pojawienia się negatywnych komentarzy konkurentów oraz możliwość umieszczania nieprawdziwych informacji (44\% badanych), co wpływa niekorzystnie na postrzeganie przedsiębiorstwa przez konsumentów (mimo że sama możliwość zamieszczania komentarzy postrzegana była pozytywnie). Kolejną barierą wg badanych były wiek odbiorcy wskazało na niego ok. $45 \%$ badanych (ok. 10\% wskazało tak w bardzo dużym stopniu, a 35\% - tak). Warto w tym miejscu zwrócić uwagę, że wystapił związek pomiędzy udzielonymi odpowiedziami a wiekiem respondentów. Szczegółowa analiza wykazała, iż barierę tę wskazywały osoby powyżej 50 roku życia. Jeśli chodzi o takie czynniki, jak: wymaga dużo czasu, jest kosztowne, to nie dotyczyły one zdaniem respondentów wykorzystania tego środka komunikacji. Kwestią nie do końca rozstrzygniętą było ograniczenie dotyczące Internetu. W tym przpadku 30\% respondentów wskazało, że jest to bariera, 36\%, że jest to tylko częściowa bariera w wykorzystaniu mediów społcznosciowych do komunikacji $\mathrm{z}$ rynkiem.

Czynniki wpływające na podjęcie decyzji o wykorzystaniu Facebooka przez badane przedsiębiorstwa do komunikacji z rynkiem przedstawiono na rycinie 6.

Poddając analizie dane przedstawione na rycinie 6, stwierdzić można, że największy wpływ na podjęcie decyzji o wykorzystaniu Facebooka w celach marketingowych mają: łatwość i prostota w wykorzystaniu (82\% badanych przedsiębiorstw), niskie koszty (46\% badanych przedsiębiorstw), globalizacja (46\% badanych przedsiębiorstw), wzmożona 
Rycina 3. Średnie oceny wykorzystania poszczególnych komunikatorów z 95-procentowymi przedziałami ufności

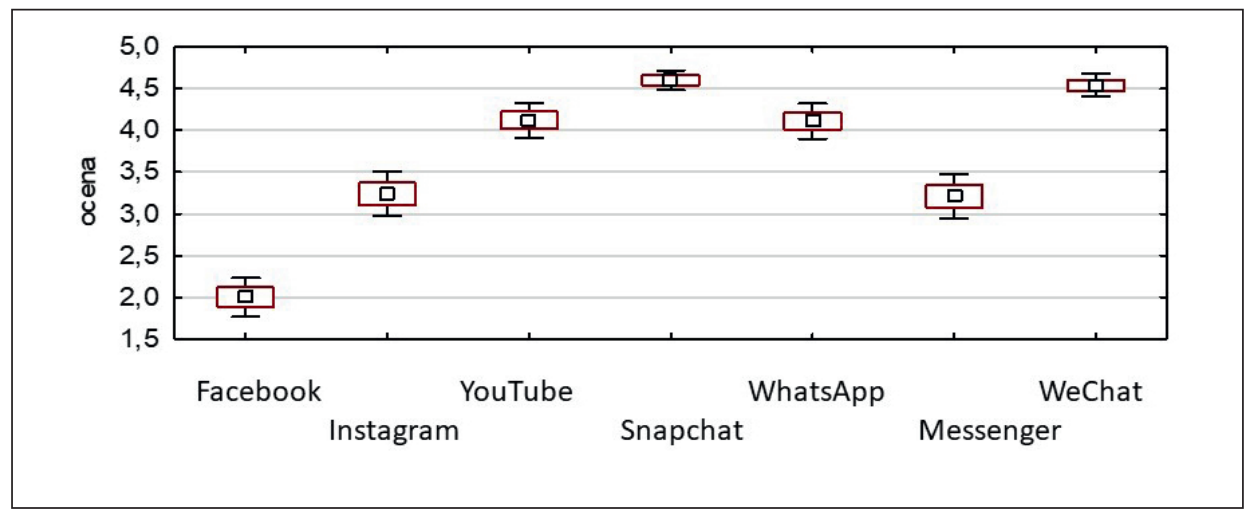

Źródło: Opracowanie własne na podstawie przeprowadzonych badań

Rycina 4. Wykorzystanie mediów społecznościowych do komunikacji z rynkiem w opinii badanych

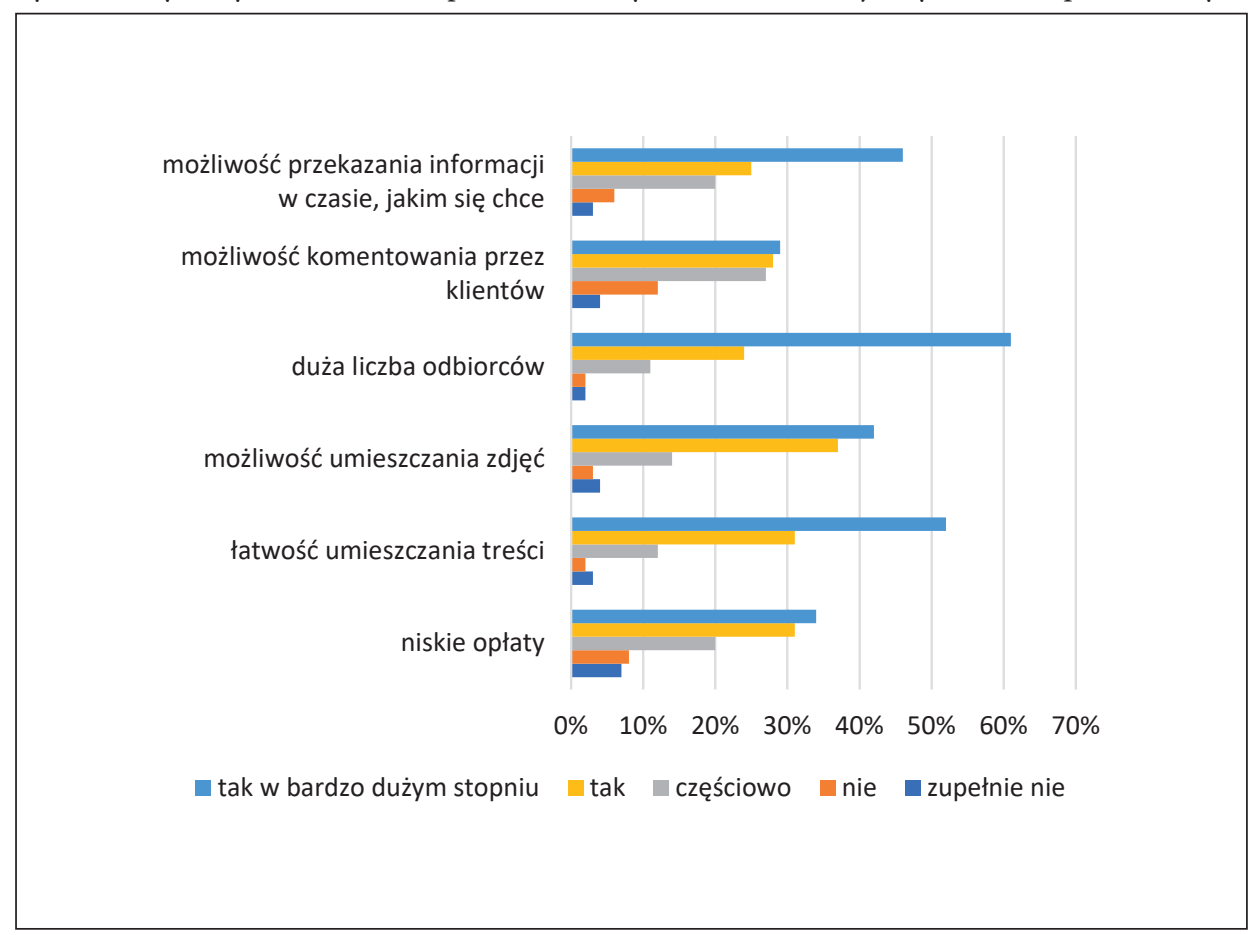

Źródło: Opracowanie własne na podstawie przeprowadzonych badań

konkurencja (30\% badanych przedsiębiorstw). Popularność Facebooka oraz możliwość precyzyjnego dotarcia za jego pośrednictwem do określonych grup konsumentów nie zostały określone jako czynnik wpływający na decyzję o korzystaniu z tego portalu. 
Rycina 5. Bariery w komunikacji z rynkiem poprzez media społecznościowe

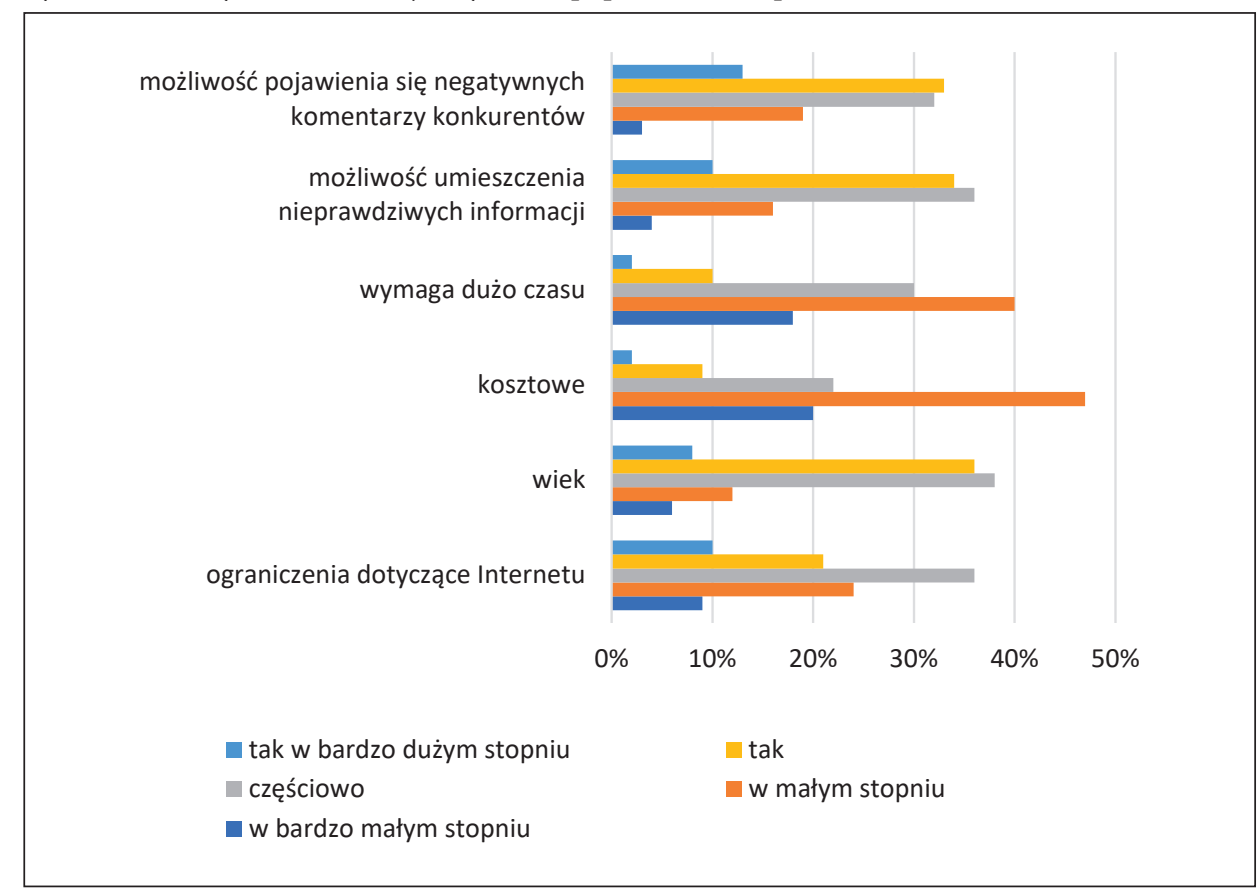

Źródło: Opracowanie własne na podstawie przeprowadzonych badań

Rycina 6. Czynniki mające wpływ na decyzje dotyczące wykorzystania Facebooka do komunikacji z rynkiem

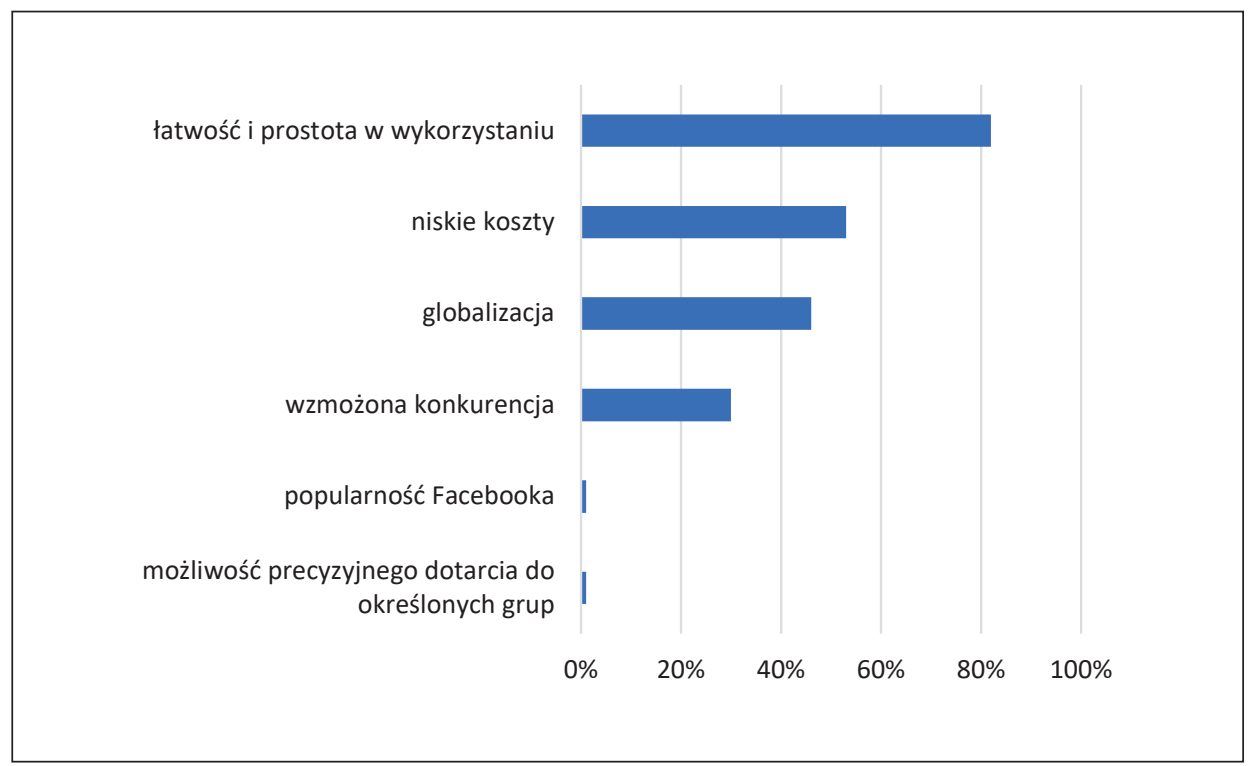

Źródło: Opracowanie własne na podstawie przeprowadzonych badań 


\section{Podsumowanie i wnioski}

Przeprowadzone badania pozwoliły zrealizować cel artykułu oraz udzielić odpowiedzi na postawione pytania badawcze. W przypadku pierwszego pytania badawczego ustalono, że najczęściej badane przedsiebiorstwa komunikowały się z rynkiem za pośrednictwem Facebooka. Następnymi wskazanymi przez respondentów komunikatorami były Messenger i Instagram. W małym stopniu w komunikcji z rynkiem małe przedsiębiorstwa wykorzystywały WhatsAppa oraz YouTube'a, a nie wykorzystywały w ogóle Snapchatu i WeChatu. W przypadku drugiego pytania badawczego spostrzeżono, że w uwarunkowaniach wykorzystania mediów społecznościowych do komunikacji z rynkiem przez małe przedsiębiorstwa występują zarówno zalety, jak i bariery. Wśród zalet badani wymienili: dużą liczbę odbiorców, łatwość umieszczania treści, możliwość umieszczania zdjęć, możliwość przekazywania informacji w czasie, w którym się chce, niskie opłaty, możliwość komentowania przez klientów, ale z drugiej 46\% badanych wskazywało jako zagrożenie możliwość pojawienia się negatywnych komentarzy konkurentów oraz możliwość umieszczania nieprawdziwych informacji. Wśród barier respondenci wymienili: wiek odbiorcy, lecz wystapił tu związek pomiędzy udzielonymi odpowiedziami a wiekiem respondentów. Szczegółowa analiza wykazała, iż barierę tę wskazywały osoby powyżej 50 roku życia. W przypadku trzeciego pytania badawczego, które dotyczyło decyzji o wykorzystaniu Facebooka do celów marketingowych przez małe przedsiębiorstwa, stwierdzono, iż decyzja ta była spowodowana następującymi cechami tego portalu: łatwością i prostotą w wykorzystaniu, niskimi kosztami, globalizjacją, wzmożoną konkurencją.

Implikacje dla małych przedsiębiorstw są takie, że mogą on podejmować lepsze decyzje dotyczące wykorzystania mediów społecznościowych w komunikacji z rynkiem. Wykorzystanie tych mediów daje im możliwość budowania relacji z klientami, umożliwia szybki, globalny przepływ informacji, a także wspiera społeczną odpowiedzialność biznesu. Niemniej jednak należy pamiętać, że dane z mediów społecznościowych są trudne do zbadania ze względu na ich objętość, różnorodność i szybkość (Arrigo, Liberati, Mariani, 2021). Klienci nie stanowią jednorodnej grupy, a ich preferencje i stopień akceptacji innowacji są różne (Gupta, Pansari, Kumar, 2018; Samiee, 2019; Torelli, Stoner, 2019). Ponieważ siła wniosków jest duża (według raportów korzystanie z mediów społecznościowych zwiększa się z roku na rok), warto w dalszych badaniach przeanalizować zagadnienia związane z selekcjonowaniem danych dostępnych w mediach społecznościowych, dbaniem o bezpieczeństwo tych mediów oraz zależnościami pomiędzy preferencjami klientów a stopniem akceptacji innowacji w zakresie komunikacji marketingowej.

Literatura

References

Arrigo, E., Liberati, C., Mariani P. (2021). Paolo Social Media Data and Users 'Preferences: A Statistical Analysis to Support Marketing Communication. Big Data Research, 24. Retrieved from: https:// www.x-mol.com/paperRedirect/1347335212817862656

Ashley, C., Tuten, T. (2014). Creative Strategies in Social Media Marketing: An Exploratory Study of Branded Social Content and Consumer Engagement, Psychology \& Marketing, 32(1), 15-27. https://doi.org/10.1002/mar.20761 
Bojanowska, A. (2018). Działania MŚP w mediach społecznościowych w świetle badań ich aktywności. Przedsiębiorczość i Zarządzanie, 19, 175-187.

Cheng, G., Cherian, J., Sial, M.S., Mentel, G., Wan, P., Álvarez-Otero, S. Saleem, U. (2021). The Relationship between CSR Communication on Social Media, Purchase Intention, and E-WOM in the Banking Sector of an Emerging Economy. JTAECR, 16, 1025-1041.

Chu, S.C., Deng, T., Cheng, H. (2020). The role of social media advertising in hospitality, tourism and travel: a literature review and research agenda. International Journal of Contemporary Hospitality Management, 32(11), 3419-3438. https://doi.org/10.1108/IJCHM-05-2020-0480.

Fine, A., Grönroos, C. (2009). Rethinking marketing communication: From integrated marketing communication to relationship communication. JOMC, 15, 179-195. https://doi. org/10.1080/13527260902757654

Gruszka, A. (2020, 20 stycznia). Chatboty, Social Media, Messenger Marketing - statystyki, które powinieneś znać w 2020 roku. Pozyskano z: https://kodabots.com/blog/chatbot-statystyki/

Gupta, S., Pansari, A., Kumar, V. (2018). Global Customer Engagement. Journal of International Marketing, 26, 4-29. https://doi.org/10.1509\%2Fjim.17.0091

Gyenge, B., Máté, Z., Vida, I., Bilan, Y., Vasa, L. (2021). A New Strategic Marketing Management Model for the Specificities of E-Commerce in the Supply Chain. JTAECR, 16, 1136-1149. https://doi. org/10.3390/jtaer 16040064

Hänninen, N. Karjaluoto, H. (2017). The effect of marketing communication on business relationship loyalty. Marketing Intelligence \& Planning, 35, 458-472. https://doi.org/10.1108/MIP-01-20160006

James, R.J.E., Bradley, A. (2021). The Use of Social Media in Research on Gambling: a Systematic Review. Curr Addict Rep, 8, 235-245. https://doi.org/10.1007/s40429-021-00364-w

Janczewska, D. (2018). Orientacja marketingowa jako kierunek wsparcia konkurencyjności mikroprzedsiębiorstwa. Przedsiębiorczość z Zarządzanie, 19, 9-21.

Heath, R.L., Johansen, W., Ju, I. (2018). Marketing Communication. In: R.L. Heath, W. Johansen (eds). The International Encyclopedia of Strategic Communication. https://doi.org/10.1002/9781119010722. iesc0102

Kaplan, A.M., Haenlein, M. (2010). Users of the world, unite! The challenges and opportunities of social media. Business Horizons, 53, 59-68. https://doi.org/10.1016/j.bushor.2009.09.003

Kijewska, J. Mantura, W. (2017). Istota komunikacji marketingowej i promocji oraz koncepcja klasyfikacji form komunikacji marketingowej przedsiębiorstwa. Handel Wewnętrzny, 6(371), 132-141.

Kozioł, K., Rudawska, I. (2007). Are we Facing a Global Consumer? Folia Oeconomica Stetinensia, 6, 88-97. https://doi.org/10.2478/v10031-007-0004-5

Kumar, V., Mirchandani, R. (2012). Increasing the ROI of Social Media Marketing. MIT Sloan Management, 54(1), 55. Retrieved from: https://sloanreview.mit.edu/article/increasing-the-roi-of-social-media-marketing/

Li, F., Larimo, J., Leonidou, L.C. (2020). Social media marketing strategy: definition, conceptualization, taxonomy, validation, and future agenda. Journal of the Academy of Marketing Science, 49, 51-70. https://doi.org/10.1007/s11747-020-00733-3

Lijuan, B., Xiangbin, Y. (2021). Impact of social media capability on firm performance: new evidence from China. Asian Business \& Management. http://dx.doi.org/10.1057/s41291-021-00156-0

Lisiński, M. (2016). Metody naukowe w metodologii nauk o zarządzaniu, Przegląd Organizacji, 4, 11-19.

Luther, B.W., Nobmann, N., Winter, H., Erdelt, T., Haensel, P.A. (2017). The Modelling and Assessment of Online Customer Interaction. Customer Journeys and Churning. https://dx.doi.org/10.2139/ ssrn. 3404493

Łuczka, T. (2009). Internet as the development factor of small and medium-sized enterprises in the conditions of internationalization and globalization. In: J. Przybysz (ed.), Creation of Social Capital. Poznań: Publishing House of Poznan University of Technology, 141-156. 
Marušić, T., Vranesevic, T. (2021). Challenges of navigating brands through social media Izazovi u upravljanju markama prisutnima na društvenim medijima iz perspektive marketing menadžera: marketing managers point of view. Ekonomski Pregled, 72(3), 413-430. http://dx.doi.org/10.32910/ ep.72.3.4

Mattelart, A. (2001). Teorie komunikacji: krótkie wprowadzenie. Warszawa: PWN.

Mirek, J. (2019; 2021, 20 stycznia). We Are Social: Cyfrowy wzrost w 2019 roku. Pozyskano z: https:// www.mobiletrends.pl/raport-cyfrowy-wzrost-w-2019-roku/

Moliner, M.A., Monferrer Tirado, D., Estrada-Guillén, M. (2020). CSR marketing outcomes and branch managers' perceptions of CSR. International Journal of Bank Marketing, 38, 63-85. https://doi. org/10.1108/IJBM-11-2018-0307

Mušanović, J., Dorčić, J., Baldigara, T. (2021). Sentiment analysis of social media content in Croatian hotel Industry. Zbornik Veleučilišta u Rijeci, 9, 37-57. https://doi.org/10.31784/zvr.9.1.3

Nuseir, M., Qasim, A. (2021). Investor relations in the era of social media: systematic literature review of social media as a strategic corporate disclosure tool. Journal of Financial Reporting and Accounting. http://dx.doi.org/10.1108/JFRA-06-2020-0160

Pawlak, J. (2016). Rola portalu społecznościowego Twitter w promocji mikro i małego przedsiębiorstwa. Finanse, Rynki Finansowe, Ubezpieczenia, 5(83), 131-138. https://doi.org/10.18276/ frfu.2016.5.83/2-12

Petrova, M., Sen, A., Yildirim, P. (2021). Social Media and Political Contributions: The Impact of New Technology on Political Competition. Management Science, 67, 2997-3021. https://doi. org $/ 10.1287 /$ mnsc. 2020.3740

Pollák, F. Markovic, P. (2021). Economic Activity as a Determinant for Customer Adoption of Social Media Marketing. Sustainability, 13, 3999. https://doi.org/10.3390/su13073999

Samiee, S. (2019). Reflections on global brands, global consumer culture and globalization. International Marketing Review, 36, 536-544. https://doi.org/10.1108/IMR-11-2018-0342

Siddiqui, M.S., Siddiqui, U.A., Khan, M.A., Alkandi, I.G., Saxena, A.K., Siddiqui, J.H. (2021). Creating Electronic Word of Mouth Credibility through Social Networking Sites and Determining Its Impact on Brand Image and Online Purchase Intentions in India. JTAER, 16, 1008-1024. https:// doi.org/10.3390/jtaer 16040057

Strokova, M. (2020; 2021, 20 stycznia). TOP 10 najważniejszych statystyk Facebooka dla marketerów w 2020 roku. Pozyskano z: https://blog.csgroup.pl/social-media/top-10-najwazniejszych-statystykfacebooka-dla-marketerow-w-2020-roku/

Sakya, S.M., Van Scoy, L.J., Garman, J.C., Miller, E.L., Snyder, B., Wasserman, E., Chinchilli, V.M., Surav, R.P.L. (2021). The impact of COVID-19-related changes in media consumption on public knowledge: results of a cross-sectional survey of Pennsylvania adults. Current Medical Research and Opinion, 37, 911-915. https://doi.org/10.1080/03007995.2021.1901679

Szymański, G. (2010). Marketing społecznościowy czynnikiem przewagi konkurencyjnej na współczesnym rynku. Zeszyty Naukowe Uniwersytetu Szczecińskiego. Ekonomiczne Problemy Ustug, 55, 589-597.

Torelli, C.J., Stoner, J.L. (2019). Global consumer culture: Consequences for consumer research. International Marketing Review, 36, 587-592. https://doi.org/10.1108/IMR-11-2018-0316

Touchette, B., Schanski, M., Lee, S.E. (2015). Apparel brands' use of Facebook: an exploratory content analysis of branded entertainment. Journal of Fashion Marketing and Management, 19(2), 107119. https://doi.org/10.1108/JFMM-04-2013-0051

Wang, R., Huang, Y. (2018). Communicating corporate social responsibility (CSR) on social media: How do message source and types of CSR messages influence stakeholders' perceptions?. Corporate Communications: An International Journal, 23, 326-341. https://doi.org/10.1108/CCIJ-07-20170067

Wang, Y.Y., Wang, T., Calantone, R. (2021). The effect of competitive actions and social media perceptions on offline car sales after automobile. International Journal of Information Management, 56. 
We Are Social, Hootsuite. (2020; 2021, 20 January). Digital in 2020: Global Overview. Retrieved from: https://datareportal.com/reports/digital-2020-global-digital-overview

Wiktor, J.W. (2013), Komunikacja marketingowa. Modele, struktury, formy przekazu, Warszawa: PWN. Wodyński, W. (2007), Strategie komunikacji marketingowej przedsiębiorstw przemysłowych, Współczesna Ekonomia, 1(3).

Social Media w Polsce 2021 - nowy raport. (2021, 4 marca). Pozyskano z: https:/empemedia.pl/socialmedia-w-polsce-2021-nowy-raport/

Magdalena Gorzelany-Dziadkowiec, dr nauk ekonomicznych w zakresie nauk o zarządzaniu, Uniwersytet Ekonomiczny w Krakowie, Kolegium Ekonomii, Finansów i Prawa, Instytut Ekonomii, Katedra Rozwoju Organizacji. Specjalizuje się w zagadnieniach związanych z konkurencyjnością organizacji, konkurencyjnością małych i średnich przedsiębiorstw, rozwojem organizacji, miast i regionów, zarządzaniem zmianami oraz systemami ICT. Jest autorką i współautorką około 36 artykułów, 25 rozdziałów w monografiach, napisała 2 podręczniki. Uczestniczyła w 46 konferencjach w kraju i za granicą. Jest laureatką 16 nagród i wyróżnień Rektora Uniwersytetu Ekonomicznego w Krakowie za osiągnięcia: naukowe indywidualne, jak również zespołowe oraz osiągnięcia dydaktyczne. Finalistka plebiscytu Mentorzy Uniwersytetu Ekonomicznego w Krakowie w roku 2020.

Magdalena Gorzelany-Dziadkowiec, $\mathrm{PhD}$ in economics in management sciences, Cracow University of Economics, College of Economics, Finance and Law, Institute of Economics, Department of Organization Development. She specialises in issues related to the competitiveness of organisations and the competitiveness of small and medium-sized enterprises. She is also interested in the development of organisations, cities and regions, management of changes and ICT systems. She is the author and co-author of about 36 articles, 25 chapters in monographs; she also wrote 2 textbooks. She participated in 46 conferences in the country and abroad. Winner of 16 awards and distinctions of the Rector of the Cracow University of Economics for individual scientific, as well as team and didactic achievements. Finalist of the Mentors plebiscite of the Cracow University of Economics in 2020 .

ORCID: https://orcid.org/0000-0001-9062-5984

\title{
Adres/Address:
}

\author{
Uniwersytet Ekonomiczny w Krakowie \\ Katedra Rozwoju Organizacji \\ ul. Rakowicka 27 \\ 31-510 Kraków, Poland \\ e-mail: gorzelam@uek.krakow.pl
}

Krzysztof Firlej, prof. dr hab., Uniwersytet Ekonomiczny w Krakowie, Kolegium Ekonomii, Finansów i Prawa, Instytut Ekonomii, Katedra Rozwoju Organizacji. Profesor zwyczajny, kierownik Zakładu Rozwoju Organizacji, kierownik Instytutu Ekonomicznego. Jego obecne zainteresowania badawcze obejmują takie dziedziny ekonomii, jak działalność polskiego i międzynarodowego przemysłu spożywczego, globalizacja, gospodarka światowa, zarządzanie przedsiębiorstwami i przedsiębiorstwami, strategie przedsiębiorstw spożywczych w świetle wspólnej polityki rolnej oraz agrobiznes na światowych rynkach.

Krzysztof Firlej, professor, Cracow University of Economics, College of Economics, Finance and Law, Institute of Economics, Department of Organization Development. Full professor, Head of the Department of Organization Development, Head of the Institute of Economics. His current research interests include the operations of the Polish and international food industry, globalisation, global economy, company and business management, strategies of food companies in the light of the common agricultural policy, and agribusiness on global markets. 
ORCID: https://orcid.org/0000-0001-7870-046X

\section{Adres/Address:}

Uniwersytet Ekonomiczny w Krakowie

Katedra Rozwoju Organizacji

ul. Rakowicka 27

31-510 Kraków, Poland

e-mail: krzysztof.firlej@uek.krakow.pl

Publikacja została sfinansowana ze środków subwencji przyznanej Uniwersytetowi Ekonomicznemu w Krakowie Program POTENCJAŁ nr 13/EER/2020/POT.w 